\title{
Suitability of Martian Regolith as Material for Future Dwellings--An Investigation by Middle School Students in Collaboration with MIT and JEOL, USA
}

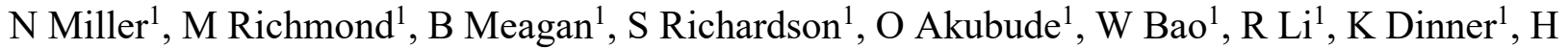 \\ Griffin $^{1}$ D Shattuck ${ }^{1,2 *}$, F Martin Martinez ${ }^{2}$, Z Qin ${ }^{2}$, M Buehler ${ }^{2}$, K Kupwade-Patil ${ }^{3}$ and V Robertson ${ }^{4}$ \\ ${ }^{1 .}$ Concord Middle School, Concord, MA, USA. \\ 2. Laboratory for Atomistic and Molecular Mechanics, Civil and Environmental Engineering \\ Department, Massachusetts Institute of Technology, Cambridge, MA, USA. \\ 3. Laboratory for Infrastructure Science and Sustainability, Civil and Environmental Engineering \\ Department, Massachusetts Institute of Technology, Cambridge, MA, USA. \\ 4. JEOL USA, Peabody, MA, USA. \\ * Corresponding author: shattuck@MIT.EDU
}

Presented here in poster format is the preliminary result of a continuing investigation conducted by nine middle school students into the mechanical properties of simulated Martian regolith and its suitability as a construction material for proposed 3D-printed Martian dwellings. These investigations have been an integral part of research being conducted at MIT's Laboratory for Atomistic and Molecular Mechanics (LAMM) [1] and in the Laboratory for Infrastructure Sciences and Sustainability (LISS) [2].

In 2015 NASA began issuing challenges for the development of innovative technologies that would support human colonization of Mars by 2050. Students began with concepts and images developed at MIT as part of the initial Habitat Challenge [3]. From there, the team, including middle and high school students, MIT researchers, and grad students, hypothesized that the most efficient and sustainable means of structural development would be to use the indigenous materials: silicon-rich basaltic regolith, the thin gaseous carbon dioxide atmosphere, and the water ice discovered by the Curiosity rover. In addition, we assume NASA's Challenge to chemically convert $\mathrm{CO}_{2}$ to simple sugars [4] and possibly starches will be successful and provide an additional structural constituent.

Our research focused on evaluating the structural capacity of a Martian regolith analog [5] and its ability to withstand compression and impact forces. For this work we evaluated three fractions of milled sorted Mojave Martian Simulant (MMS-1)—Superfine $(<0.5 \mathrm{~mm})$, Fine $(0.5-1.27 \mathrm{~mm})$, Coarse $(1.27 \mathrm{~mm}$ $3.17 \mathrm{~mm})$ and Unsorted $(<3.17 \mathrm{~mm})$; each with differing total surface area available for binding and adhesion. For this investigation commercially available casein-based "milk glue" and saccharide-based flour-water paste were evaluated. Water was used as a control. In addition, samples of the Fine fraction were vitrified with the assistance of the Department of Energy's Pacific Northwest National Laboratory (PNNL).

Each regolith sample was mixed with an equal volume of binding agent, formed in a $6 \mathrm{~cm}$ circular mold, pressed to a thickness of approximately $1 \mathrm{~cm}$, and allowed to air dry for seven to 14 days. Afterward, each sample was centered on a frame that supported the outside edge. A $6 \mathrm{~cm}$ spherical weight was dropped from increasing heights to determine the force needed to catastrophically fracture the regolith.

The milk glue mixture exhibited the greatest fracture resistance. Samples were subsequently tested with a reduced the ratio of regolith to glue from 1:1 to 1:0.66 and 1:0.5. Both exhibited substantially greater strength, similar to the grain size related findings of Kupwade-Patil et al [2]. 
Based on our observations, we believe Martian regolith may become a viable construction material but additional work will be necessary to produce a binding material that will be suitable for building sound, impact-resistant dwellings. In addition to reinforcing concepts developed during research, this activity dramatically demonstrates the links among public school learning, academic research, and the private sector that supports them [6].

References:

[1] SD Palkovic et al., Construction and Building Materials 115 (2016), p. 13.

[2] K Kupwade-Patil et al., J. Mater. Civ. Eng. 30(8) (2018), p. 04018190.

[3] http://news.mit.edu/2017/mars-city-living-designing-for-the-red-planet-1031

[4] https://www.nasa.gov/solve/CO2_Conversion_Challenge

[5] GH Peters et al., Icarus 197 (2008), p. 470.

[6] The authors thank the Laboratory for Atomistic and Molecular Mechanics, and the Laboratory for Infrastructure Science and Sustainability at MIT, Bradley Johnson, Connor Appel, and Michael Schweiger at the Pacific Northwest National Laboratory, and the educational outreach of JEOL, USA.

\section{川i而 \\ Suitability of Martian Regolith as Material for Future Dwellings \\ N. Miller', M Richmond', B Meagan', S Richardson'1, O Akubude'1, W Bao', R Li', K Dinner', H Griffin', D Shattuck'2,

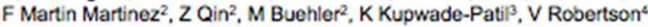 1 Concord Middle School, Concord, MA, USA. \\ 2 Laboratory for Atomistic and Molecular Mechanics, Civil and Environmental Engineering Department. Massachusetts Institute of Technology. Cambridge, MA, USA. 3 Laboratory for Infrastructure Science and Sustainability, Civil and Environmental Engineering Department, Massachusetts Institute of Technology, Cambridge, MA, USA. 4 JEOL USA, Peabody. MA, USA.}

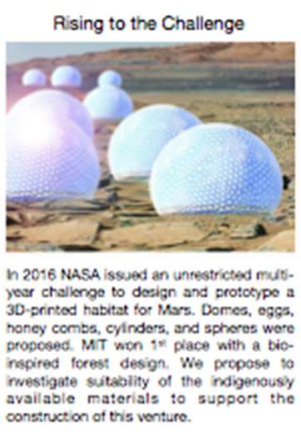

Impact Resistance Testing

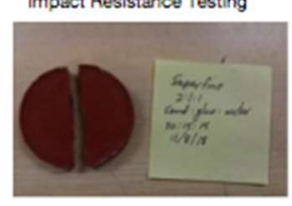

Two binding moterials-cestein based
milk give and flourwator paste-were rixod with sorted and unsotod rogolten ard formod into $6 \mathrm{~cm}$ dses. Dases were trame and impect lested by dropen frame and mpact-tested by dropping a needed to cause failure.

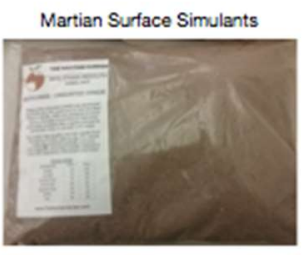

Much of the Murtian serbace is covered whe eroded basatic material than has beten tithologicaty and chomically charactorized
Ey NASA In adeition. NASA has iscreffed by NASA in sdeition, NASA has idertfied
terrestrial locatons tha: have similar

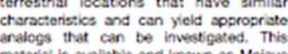
meletial is aralabie and known as Mojave

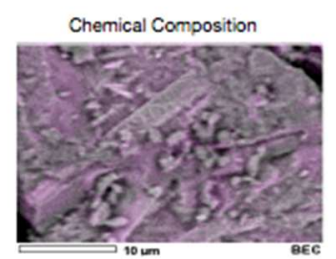

An energy dispersive spectrograoh $x$-Pay map of simulant indicates a relatively low amount of Cascium (purple), the materis in
cerment thet is respons bie for the formation of cement that is respons bie for the formation of on a $2500 x$ SEM image of super fine sifed on a $2550 x$ seM image of super fine Mertian Simulert.

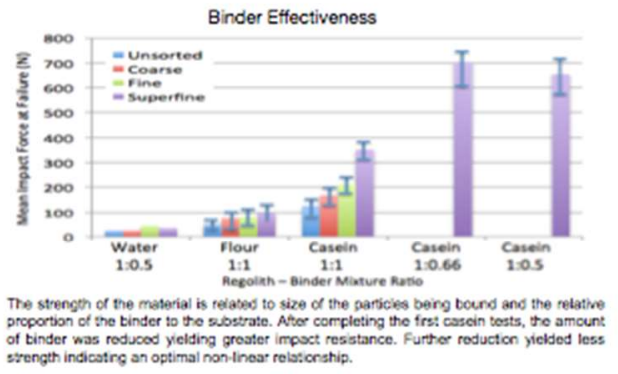

of tinder was roducoos yelding groster impost ressitance. Furter roducton, yielded less stength indicastrg an optimal non tinear relustcreship.

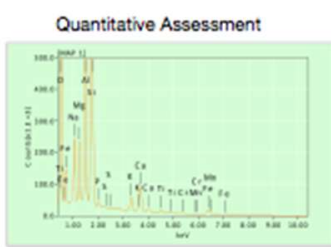

Shown abovo is an EOS $X$-ray andyeis of the chemices compasition of a point on the Mers simuant map, The Calcim peaks (Ca) at 3.6 and $4,0 \mathrm{keV}$ indease redatively smal amounte of Cas. teOL's assessment is tha cao construtos mplication is that cementation is unikelly and that a binder or achesive will be needed,

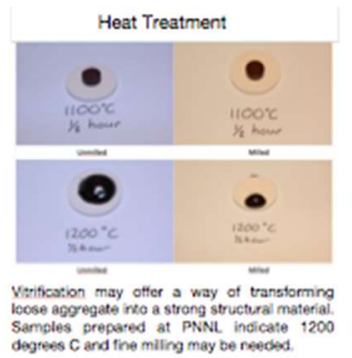

Conclusions and Future Investigation Based on our preliminary setwity, we foel that the Martian soll is a plausible bulding material because: - In adscros water and cant be shaged by extrusian water ans cor be shaped oy - Wen a sutwibio binder, it can be formod into good struetural materad thas can witheling acernal impact

Asciabe cogaric bincer needs to be deveiosed

- Devecicpment of a sutable binder - Desion of corstruetion equpment

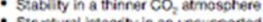

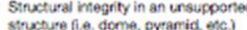
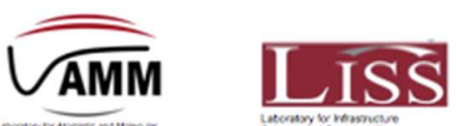
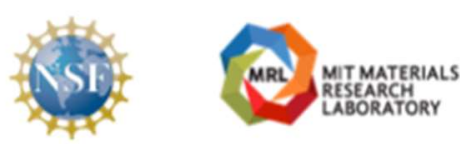

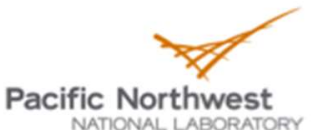

JEOL 